\title{
Mobile learning e gamification: estratégias para promoção de direitos e ampliação da inteligência coletiva
}

\author{
Elias R. Oliveira ${ }^{1,2}$, Juliana R. B. Diniz ${ }^{1}$ \\ ${ }^{1}$ Programa de Pós Graduação em Tecnologia e Gestão em Educação a Distância - \\ Universidade Federal Rural de Pernambuco [UFRPE] \\ Polícia Civil de Pernambuco (PCPE) \\ CEP - 55.819-270 - Recife - PE - Brasil \\ \{eliasrick872@hotmail.com, julianabdiniz@gmail.com
}

\begin{abstract}
This paper proposes the use of mobile learning combined with gamification strategies for the promotion of consumer rights thus expanding collective intelligence. Therefore, this research is presented with primary data demonstrating responsiveness in profile, and in needs of the target audience, highlighting the importance of an educational support to reach this student/consumer beyond the limits of traditional classroom or even the elearning methodology.
\end{abstract}

Resumo. O presente artigo propõe a utilização do mobile learning com estratégias de gamificação para a promoção dos direitos dos consumidores ampliando assim a inteligência coletiva nesta temática. Para tanto, essa pesquisa é apresentada com dados primários demonstrando a receptividade tanto no perfil, quanto na necessidade do público-alvo, salientando a importância de um suporte educacional que atinja este aluno/usuário/consumidor para além dos limites da sala de aula tradicional ou até mesmo a educação a distância.

\section{Introdução}

A sociedade contemporânea consome produtos e serviços diuturnamente. Esta mesma sociedade encontra-se imersa em tecnologia. Neste ponto, encontra-se uma estreita relação entre consumo, tecnologia e aprendizagem.

O ato de consumir não se resume necessariamente a uma ação temporária e contingente, uma simples satisfação das necessidades físicas ou psicológicas do indivíduo ou algo dispendioso e supérfluo [Mazetti 2012], vai além do ato de consumir. Ainda, segundo autor, diversos estudos recentes vêm corroborando para uma melhor compreensão deste fenômeno: $\mathrm{o}$ consumo, já que de forma prática e numa perspectiva de mercado, o consumidor se tornou um privilegiado objeto de saber com diversas pesquisas empíricas a fim de decifrar o que torna um consumidor fiel e o que o afugenta.

Neste contexto, diversas são as instituições que tentam formar consumidores mais conscientes e outras entidades jurídicas, também colaboram para divulgar e defender os direitos dos consumidores [Mazetti 2012].

Neste ponto, destacamos o Estado, que por meio de políticas públicas possa promover a defesa dos direitos desses consumidores/cidadãos frente aos inúmeros problemas enfrentados nas relações de consumo, nos casos em que esse direito não é respeitado.

Por outro lado, de que forma pode o poder público, através de uma política pública, promover a defesa dos direitos dos consumidores por meio da tecnologia? 
Embora esta questão não seja respondida de forma tão simples, ela pode encontrar eco na aprendizagem móvel. É sabido que a tecnologia avança a cada dia e para se ter um exemplo os celulares vem ocupando muito espaço entre os brasileiros. Em estudo divulgado e disponível pela [ANATEL 2015] o Brasil registrou, em agosto de 2015, 280,02 milhões de linhas ativas na telefonia móvel, ou seja, existem mais linhas ativas que a população do país. Segundo relatório da UNESCO, em 2014, milhões de pessoas não liam por um motivo: não possuíam acesso a textos. Mas atualmente telefones móveis e redes celulares estão transformando um recurso escasso em abundante [UNESCO 2014].

Nesta pesquisa, a aprendizagem móvel ou m-learning surge como suporte para a promoção de educação de conceitos relacionados ao Código de Defesa do Consumidor (CDC) - Lei que defende o direito dos consumidores no Brasil, pois este tipo de aprendizagem permite qualquer pessoa acessar informação e materiais de estudos de qualquer lugar e a qualquer momento [Traxler 2009] [Geddes 2004)].

Para Traxler (2009), alguns defensores da aprendizagem móvel tentam defini-la e contextualizá-la em termos de dispositivos e tecnologias; outros definem e conceitualizam em termos de mobilidade dos aprendentes e da mobilidade da aprendizagem e relacionada à experiência dos aprendentes com a aprendizagem através de dispositivos móveis.

Dessa forma, a presente pesquisa propõem de forma pedagógica um protótipo com vistas a estreitar o poder público e o cidadão, especialmente na temática do CDC. A partir desse protótipo será construído um aplicativo com enfoque na aprendizagem a ser disponibilizado por meio da Polícia Civil de Pernambuco e da Universidade Federal Rural de Pernambuco, ambas instituições públicas, a primeira a nível estadual e a segunda federal.

A hipótese levantada por esta pesquisa é a de que a inteligência coletiva possa ser difundida por meio da aprendizagem aliada a gamificação. Neste sentido, o usuário/aprendente do aplicativo poderá sair de mero espectador/receber de informações e sentir-se protagonista pois será peça-chave para colaborar com outros consumidores a despeito de suas experiências nas relações de consumo. Desta forma é apresentado neste artigo o resultado de pesquisa realizada com dados primários que identificaram sob a ótica dos consumidores/cidadãos a os principais problemas enfrentados nas relações de consumo, o perfil tecnológico desse público alvo e a receptividade Deles no uso de tecnologias móveis.

\section{Mobile learning, Gamefication e Inteligência Coletiva}

Segundo Torrisi-Steele (2009), mobile learning baseia-se na integração de dispositivos móveis durante a aprendizagem, promovendo assim uma aprendizagem ativa e criativa através da promoção de espaços de aprendizagem, acabando com as limitações físicas e temporais da sala de aula tradicional. Já a gamificação (do inglês gamification) pode ser entendida através do uso de elementos, mecânicos e estéticos de jogos fora do seu ambiente original previsto para tanto [Kapp 2012].

É possível perceber entre os conceitos apresentados a estreita relação com a tecnologia, o primeiro com foco na mobilidade, pois qualquer pessoa pode transportar uma ferramenta de aprendizagem no bolso [Keegan 2005], o segundo, ganhando força nos últimos cinco anos especialmente na área educacional [Borges et al 2013].

O relatório do Gartner Group publicado em 2012 previa que até o ano passado, cerca de $50 \%$ de todo o processo de inovação mundial seria gamificado [Vianna et al., 2013]. São muitas as possibilidades do uso de elementos de jogos em áreas da aprendizagem, como no 
caso, por exemplo, o desafio, objetivos, níveis, sistema de feedback e recompensa [Salen and Zimmerman, 2012] [Mcgonigal, 2011].

No escopo desse artigo, utilizaremos estratégias que vão além do ganhar prêmios. Um exemplo da utilização destas características é apresentado por Veiga et al. (2015) no desenvolvimento do $\operatorname{LUDOS}^{1}$ para aplicação da gamificação em ecossistemas de e-learning. Em linhas gerais o software armazena dados que são relacionados a mecanismos de jogos presentes em objetos de aprendizagens dentro do ecossistema do e-learning, promovendo a recompensa e "visibilidade de progresso, como pontos obtidos ao concluir um teste, uma medalha ao concluir um desafio ou um título por completar atividades opcionais" [Veiga et. al 2015].

Outro exemplo tradicional do uso da gamificação foi o utilizado por Ferreira et al. (2015), com objetivo de promover o engajamento de estudantes ao utilizarem a ferramenta educacional Classroom eXperience (CX), uma plataforma desenvolvida pelos autores para captura de aulas no uso de equipamentos ubíquos (lousa eletrônica, microfones, câmeras de vídeo e projetores). Neste processo, os usuários da $\mathrm{CX}$, são recompensados sempre que acessam o ambiente ou quando classifica uma aula assistida, bem como, participa respondendo de forma correta a questionamento disponibilizado pelo instrutor.

Embora tenhamos o uso da gamificação da forma como foi concebido, com aspectos de mecânicas dos jogos (sistema de pontuação, recompensa, níveis, etc.) [Kapp, 2012], seu uso é bem diversificado e tem tomado outras proporções. Como exemplo, citamos o jogo apresentado por McGonigal (2016) que trata da realidade alternativa (Alternate Reality Games - ARGs), com objetivos específicos na resolução de problemas reais. Um dos jogos criados pela autora foi o Find The Future ${ }^{2}$, desenvolvido na biblioteca pública de Nova York, teve por objetivo principal a escrita de um livro em uma noite por um grupo de pessoas. Desta forma quinhentas pessoas conseguiram, com pistas espalhadas na biblioteca, escrever o livro intitulado "100 Ways To Make History"3.

Outra iniciativa é a promovida pela Universidade de Harvard nos E.U.A., através da National Science Foundation no projeto Social Aspects of Immersive Learning (Aspectos Sociais de Imersão no Aprendizado, em tradução livre). Neste projeto os jovens são convidados a vivenciar problemas a partir da visão do outro. O jogo SailMUVE ${ }^{4}$ busca a empatia entre os jogadores. É ambientado em um campo de golfe e o jogador protagonista realiza a tomada de decisões na perspectiva do proprietário do local e do guarda-florestal. Um dos principais objetivos é chegar a um consenso sobre o destino de uma lagoa e das terras naturais em volta do campo de golfe. Os idealizadores do jogo indicam que benefícios são alcançados pelos seus usuários, como a melhora de suas ações em conflitos e um maior comprometimento com o próximo [Marietta, 2013].

Estes são exemplos de jogos que visam mais que a diversão ou o ganho de prêmios, sejam em recursos financeiros ou pontuações diversas. Promovem a colaboração, sendo estes pares coautores e construtores de vários processos de significação, atuação e criação [Alves, Hetkwoski and Japiassu, 2006].

\footnotetext{
${ }^{1}$ do latim significa jogos e diversão.

${ }^{2}$ https://janemcgonigal.com/play-me/

${ }^{3}$ https://janemcgonigal.files.wordpress.com/2010/12/100waystomakehistory.pdf

${ }^{4}$ http://isites.harvard.edu/icb/icb.do?keyword=sail\&pageid=icb.page580906
} 
Diana et al. (2014) salientam que a gamificação pode provocar nos usuários um sentimento de satisfação e bem estar, sendo possível sua utilização para "engajar funcionários e motivar alunos na realização de atividades", ressaltando ainda a necessidade de um planejamento de como, onde e quando essa tecnologia deva ser utilizada.

Através dos jogos é possível realizar transformações no mundo [Mcgonigal, 2011], e neste sentido, podemos utilizar dos mecanismos existentes na gamificação, da forma não tradicional com pontos e jogos efetivamente, contudo, da forma mais altruísta Diana et al. (2014) por meio da tecnologia móvel. Este aprendente/usuário utilizará de informações que serão úteis no seu dia a dia bem como daqueles que estiverem ao seu redor. A proposta é disponibilizar ao consumidor um aplicativo que ofereça, além das informações sobre seus direitos, estratégias de compartilhamento e colaboração entre seus pares nesta mesma temática.

Recentemente uma consumidora relatou na delegacia do consumido que ao ter seu direito lesado numa loja de departamentos, quando estava a adquirir toalhas e estas estavam com preços menores, foi impedida pela gerência de levar a quantidade que almeja, sendo limitada a 5 unidade apenas, isto incompatível com a legislação ${ }^{5}$, desta forma outros consumidores se sensibilizaram e cada um na fila do caixa passou a adquirir 5 peças do produto, apenas deixando que a consumidora efetiva o pagamento. É possível perceber que atitudes como estas encontrariam ampla aceitação entre os consumidores quando socializadas e àqueles que promovessem a divulgação do conhecimento encontrariam o prazer da gamificação.

Este compartilhamento de informações nos remete ao conceito de inteligência coletiva que é deve ser considerada uma inteligência distribuída por toda parte, constantemente valorizada, coordenada em real time, que resulta em uma mobilização efetiva das competências [Lévy, 2003, 2007]. Segundo o referido autor, a coordenação dos inteligentes coletivos ocorre por meio de ferramentas das tecnologias da informação.

A colaboração e cooperação por meio de processos de aprendizagem fortalecem essa inteligência coletiva [Santos, 2008]. Todo este processo no espaço onde ocorre a participação e criação de aquisição e demonstração conhecimento é um retrato da sociedade, conquanto a inteligência coletiva "é o seu lado mais emancipador, democrático, participativo." [Moraes, 2011].

\section{Metodologia}

A natureza desta pesquisa é aplicada, pois busca uma abordagem prática para a solução de um problema específico [Marconi e Lakatos, 2010]: direcionar o cidadão para o órgão competente na solução de seu problema na relação de consumo. $\mathrm{Na}$ abordagem do problema, devido a produção de dados primários e o levantamento dos secundários, optou-se por uma abordagem quantitativa.

Neste ponto, a possibilidade do potencial dos dispositivos móveis na promoção da inteligência coletiva por meio da aprendizagem, revela uma pesquisa descritiva, onde busca caracterizar o fenômeno estudado, bem como explicativa, já que objetiva identificar os fatores das causas deste fenômeno [Gil, 2007].

\footnotetext{
${ }^{5} \mathrm{O}$ art. 39, I, do CDC versa que "É vedado ao fornecedor de produtos ou serviços, dentre outras práticas abusivas: condicionar o fornecimento de produto ou de serviço ao fornecimento de outro produto ou serviço, bem como, sem justa causa, a limites quantitativos".
} 
O público-alvo foi definido por amostragem levando-se em consideração a quantidade de cidadãos que se dirigem até a delegacia de polícia do consumidor de Pernambuco para buscar informações acerca de algum problema sofrido na relação de consumo, ou seja, todos os pesquisados possuem estreita relação de interesse com o objeto de estudo desta pesquisa.

Um pré-teste foi realizado, já que o questionário a ser aplicado deve seguir algumas regras básicas, dentre elas a de seguir uma lógica interna, na estrutura da aplicação, tabulação e interpretação, conforme orientado por Manzato e Santos (2016). Com isto, o pré-teste foi realizado com 20 pessoas a fim de identificar as áreas de confusão potencial.

Após o pré-teste, foi calculada a amostra tomando-se por base a quantidade de boletins de ocorrência registrados no período de 10/10/2015 a 10/04/2016, ou seja, seis meses. Foram registrados neste período 613 BO's de acordo com o sistema de Informações Policiais (INFOPOL).

A fórmula utilizada para o cálculo da amostra desta população finita (613 BO’s), considerou uma amostragem a ser realizada em cima do número das médias dos registros realizados nos últimos 6 meses, ou seja 613/6=102,16 (definido 103), considerando o erro amostral de 5\% e com nível de confiança em 95\%, conforme sugerido por Santos (2016). O resultado apresentou necessidade de pelo menos 81 pesquisados na amostra.

\section{Apresentação dos Resultados}

A pesquisa ocorreu entre os dias 27/03/2016 a 07/05/2016. Foram pesquisados 84 cidadãos/consumidores que buscaram a delegacia do consumidor para obter informações e/ou fazer um boletim de ocorrência relatando algum problema na relação de consumo.

O questionário apresentado aos pesquisados continha 17 perguntas, além de questões iniciais referentes ao perfil dos respondentes. Embora as perguntas seguissem uma numeração única, para efeito metodológico, o mesmo está divido em duas partes: questões 1 a 9 apresentam conteúdo voltado para informações referentes ao direito do consumidor e da 10 à 18 o foco é relacionado a conhecimentos que tratam da tecnologia, uso da internet e aplicativos móveis.

Entre os gêneros masculino e feminino disponíveis na pesquisa, constatou-se que $36,9 \%$ são homens e $63,1 \%$ mulheres. Com relação a faixa etária de ambos os gêneros, os resultados são apresentados na tabela 1 .

Tabela 1: Divisão dos pesquisados por faixa etária

\begin{tabular}{|c|c|}
\hline Faixa Etária & Percentagem \\
\hline 16 a 19 anos & $7,1 \%$ \\
\hline 20 a 29 anos & $20,2 \%$ \\
\hline 30 a 39 anos & $32,1 \%$ \\
\hline 40 a 49 anos & $25 \%$ \\
\hline 50 a 59 anos & $7,1 \%$ \\
\hline 60 a 69 anos & $7,1 \%$ \\
\hline 70 anos ou mais & $1,4 \%$ \\
\hline
\end{tabular}

Na primeira questão da pesquisa: "você conhece o código de defesa do consumidor?" $56 \%$ dos respondentes afirmaram que sim contra $44 \%$ que disseram desconhecer. Em seguida, foram perguntados se "com exceção de hoje aqui na delegacia, você já passou por algum problema em que teve seu direito, enquanto consumidor, lesado?" Neste quesito, 60,7\% afirmaram que sim, já tiveram problema além daquele que os levaram até a delegacia naquele momento, em contrapartida, $30,3 \%$ responderam negativamente. 
V Congresso Brasileiro de Informática na Educação (CBIE 2016)

Anais dos Workshops do V Congresso Brasileiro de Informática na Educação (CBIE 2016)

Buscou-se identificar também que tipo de problema na relação de consumo o respondente já enfrentou, Foi disponibilizado para os respondentes os mesmos problemas disponíveis no ranque das reclamações nacionais relacionados pelo Ministério da Justiça ${ }^{6}$ entre o período de maio de 2014 a fevereiro de 2016 e o resultado é apresentado no gráfico 1 . As respostas constantes na opção "outros" foram relacionadas a posto de combustível, questões relacionadas a contratos diversos, curso digital, concessionária de automóveis e faculdade privada.

\section{Gráfico 1: Principais problemas enfrentados pelos consumidores}

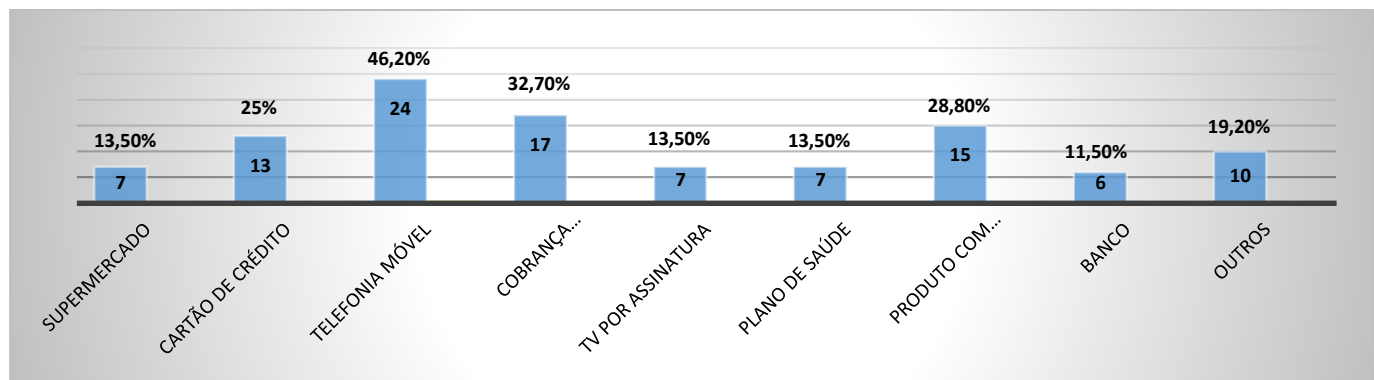

Assim como nesta pesquisa realizada, os dados apontados pelo portal consumidor.gov.br apontam que as principais reclamações referem-se a cartão de crédito/débito/loja $(9,4 \%)$, telefonia móvel pós-paga $(9,3 \%)$, TV por assinatura $(8,7 \%)$, aparelho celular $(7,9 \%)$, telefonia fixa $(6,3 \%)$, telefonia móvel pré-paga $(6,2 \%)$, pacote de serviços - combo $(5,4 \%)$, internet fica $(5,3 \%)$, internet móvel $(4,3 \%)$ e poupança/conta aposentadoria/conta corrente/salário somam 3,4\% das reclamações. Quando perguntados se "chegou a procurar algum órgão de defesa do consumidor?", obteve-se praticamente um equilíbrio, pois 50,9\% disseram que sim, enquanto 49,1\% não. Para os que procuraram, responderam em "qual o órgão chegou a procurar?", observa-se que o juizado especial civil e o PROCON foram os mais procurados, como pode ser observado no gráfico 2.

Para aqueles que buscaram ajuda nos órgãos competentes foi questionado se "acredita ter recebido a orientação correta para a solução de seu problema?" Temos que $65,7 \%$ responderam que sim, contra $34,3 \%$. Esta informação é importante tendo em vista que a percepção do consumidor enquanto aprendente ao buscar ajuda termina por ser um multiplicador das informações recebidas.

\section{Gráfico 2: Órgãos que o consumidor comunicou sobre fato na relação de consumo}

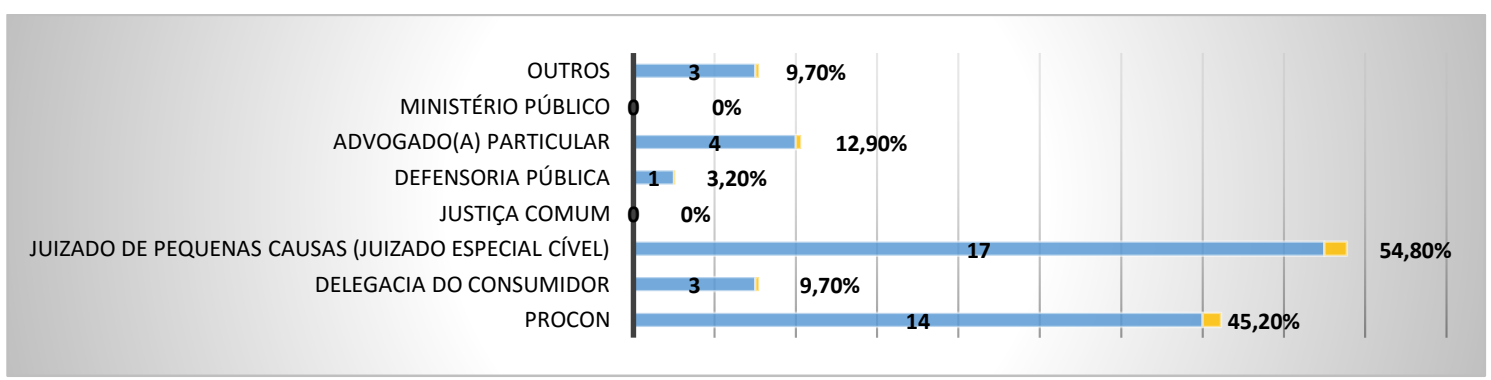

De ordem didática foi perguntado se "já viu ou participou de alguma palestra/curso sobre o direito do consumidor?" Dos respondentes, 89,9\% disseram "não", contra 13,1\% que responderam "sim". Embora muitos consumidores de fato não participam de atividades presenciais como cursos ou palestras, optamos ainda por questionar se "já viu alguma reportagem em TV, rádio

${ }^{6}$ Consumidor.gov.br 
V Congresso Brasileiro de Informática na Educação (CBIE 2016)

Anais dos Workshops do V Congresso Brasileiro de Informática na Educação (CBIE 2016)

ou jornal sobre o direito do consumidor?' Neste caso houve uma inversão nas respostas, pois 79,8\% responderam sim, quanto $20,2 \%$ não. O que demonstra o alcance de mídias específicas frente a proposição de temas relevantes para a informação da população. Ainda na percepção desde consumidor, perguntado sobre se "aprendeu algo sobre seus direitos?", em relação a questão anterior, $82,2 \%$ disseram ter aprendido, contra 17,8\%. Mais uma vez, a percepção do aprendente quanto a lembrança de algo presenciado mesmo que através de reportagem em TV, rádio ou jornal.

A segunda parte do questionário, para efeito didático metodológico, refere-se a questões sobre o uso da tecnologia. Na primeira questão, embora pareça óbvia em dias atuais, ela é necessária devido a necessidade e o oferecimento de um aplicativo ao público-alvo desta pesquisa. Neste quesito, foi questionado se os sujeitos "utilizam internet no dia a dia?". O resultado foi que 78,6\% marcaram sim, contra 21,4\%. Já para o uso de dispositivos móveis em "faz uso de dispositivo móvel (celular, tablete, etc)?" a pergunta foi quase unânime, e $94 \%$ responderam sim e apenas $6 \%$ não.

No uso do sistema operacional, foram questionados sobre "qual o sistema operacional?" o seu dispositivo móvel utilizava. Tal questionamento tinha por base validar informação mencionada por Oliveira e colegas (2015) onde descrevera o crescente uso do sistema operacional Android frente os demais sistemas. O gráfico 3 apresenta o resultado obtido.

\section{Gráfico 3 - Sistemas operacionais utilizados por consumidores}

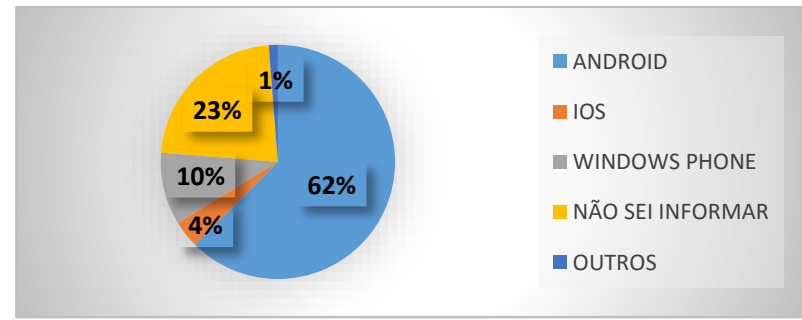

A única exceção respondida em "outros" nesta questão refere-se a um telefone comum, que não é um smartphone. Todos os outros, mesmo os que responderam "não sei informar" possuíam aparelhos com sistema operacional. Outra questão importante para base desta pesquisa, foi quanto ao uso do dispositivo móvel pelo usuário, já que aqui se pretende disponibilizar um aplicativo que seja de fato útil ao aprendente. Questionados sobre "para que mais utiliza o smartphone?" obteve-se as seguintes respostas apresentadas no gráfico 4.

\section{Gráfico 4 - Principais usos no smartphone}

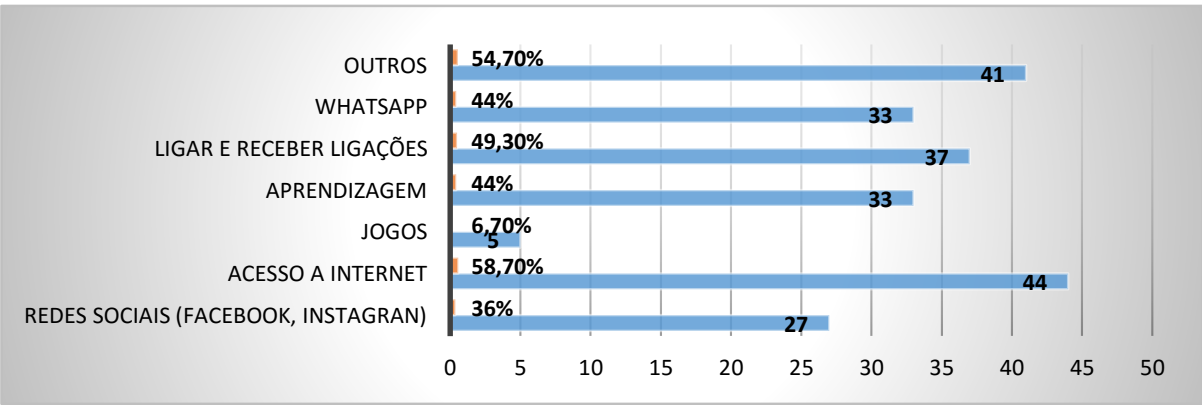

Embora muitos tenham respondido a opção "outros" e tivessem espaço para descrever para que mais utilizavam o smartphone, apenas três foram descritas, a primeira utilizava como ferramenta principalmente para áudio, devido uma deficiência visual, e as outras duas como ferramenta de trabalho/negócios.

Ao serem perguntados sobre se "utiliza com frequência aplicativos de seu smartphone?", 72,6\% afirmaram positivamente, enquanto 27,4\% disseram não usar APP's. Já 
V Congresso Brasileiro de Informática na Educação (CBIE 2016)

Anais dos Workshops do V Congresso Brasileiro de Informática na Educação (CBIE 2016)

em relação se "tem algum aplicativo instalado para aprendizagem?", 57,1\% responderam que sim, enquanto $42,9 \%$ negaram.

As duas próximas questões referem-se a utilização de algum aplicativo com conteúdo voltado para a defesa dos direitos do consumidor, tendo sida respondida positivamente por $77,8 \%$ e negativamente por 22,2\%. Quando perguntados se "lembram qual foi?" $86,5 \%$ disseram que não lembravam e 13,5\% que lembravam, contudo não escreveram em espaço disponível para que citassem qual aplicativo tenha utilizado para tratar de seus direitos enquanto consumidor.

A última questão referia-se a uma ação possivelmente esperada pelo se no "caso existisse um aplicativo voltado para o ensino sobre as leis do consumidor, você acredita que faria o download/baixaria o aplicativo?" sendo as respostas quase uma unanimidade nesta questão com $94 \%$ afirmando que sim e $6 \%$ não.

\section{O Aplicativo}

Com os dados obtidos através dessa pesquisa supracitada, foi possível idealizar um protótipo de um aplicativo de cunho educativo com enfoque no direito do consumidor, que utilize como aporte teórico, a gamificação e a inteligência coletiva.

Além disto, outros fatores que também balizaram a produção do aplicativo, tomaram como base a revisão sistemática da literatura apresentada por Oliveira, Diniz \& Pontual (2016) que mapearam quais aplicativos foram citados nos anais do Simpósio Brasileiro de Informática na Educação (SBIE), na Revista Novas Tecnologias na Educação (RENOTE) e nas Revistas de Direito da Fundação Getúlio Vargas (FGV), Universidade de Santa Cruz do Sul (UNISC) e na Universidade Federal de Minas Gerais (UFMG), nos últimos 6 anos. Tal revisão é importante, pois demonstra um panorama de que teorias estão sendo aplicadas no desenvolvimento destes APP's e suas áreas de conhecimento.
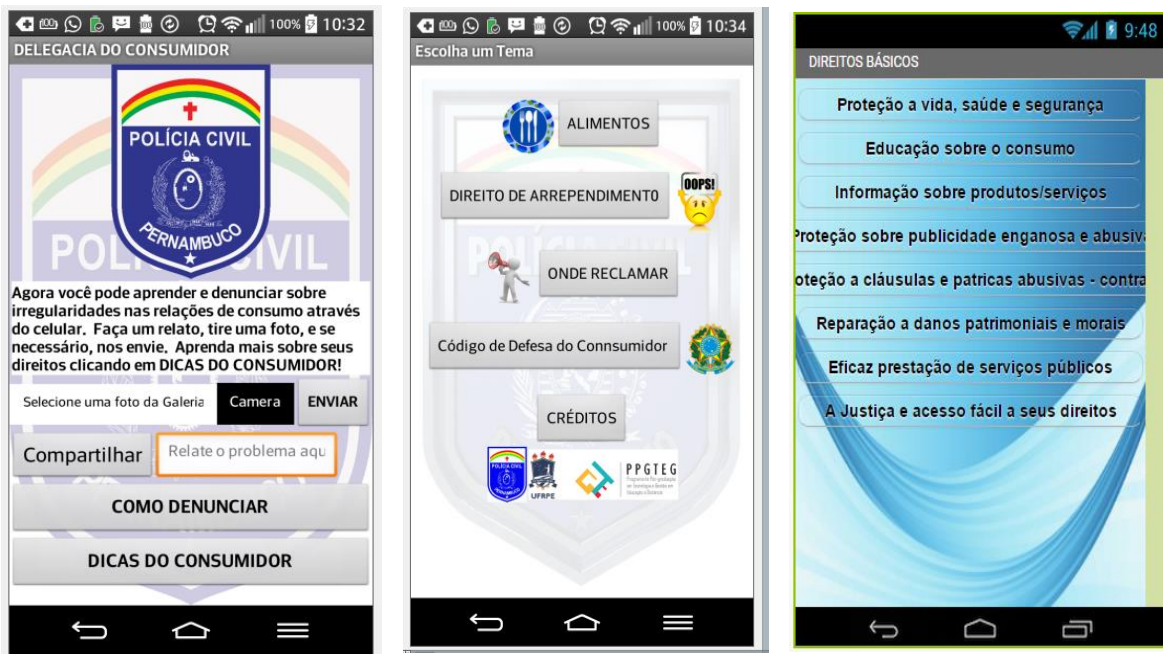

Figura 1 - Telas do Protótipo "ConsumidorAtento"

Neste ponto o desenvolvimento do protótipo já foi inicializado e já conta com as primeiras telas iniciais, conforme figura 1. A produção foi realizada através da plataforma APPInventor $2^{7}$. Na tela inicial do protótipo já é possível utilizar algumas funções, como o uso da câmera do celular para tirar fotos e/ou enviar alguma já existente como prova de denúncia

\footnotetext{
${ }^{7}$ http://ai2.appinventor.mit.edu/
} 
ao órgão competente. O botão 'dicas do consumidor" possui a função de trazer o conhecimento sobre o CDC destrinchado pedagogicamente para que o usuário possa aprender mais, este botão/link revela a segunda tela, onde é exibido conteúdos relacionados a alimentação, direito de arrependimento, informações sobre o próprio CDC e créditos. Na terceira tela é possível destrinchar os direitos básicos, relacionando-os ao dia a dia do usuário.

Além destes, um espaço reservado para compartilhamento de experiências entre consumidores, proporciona uma empatia dos usuários frente a gamificação, ou seja, poderão expor boas práticas e sentirem-se com sensação do dever cumprido ajudado outras pessoas nas relações de consumo.

\section{Conclusão e trabalhos futuros}

O principal objetivo desta pesquisa é empoderar o consumidor para que ele possa ser o protagonista nas relações de consumo, conhecedor de seus direitos e sabedor de onde, como e quando buscar ajuda no órgão competente. A hipótese de que isto é possível, baseia-se na utilização de tecnologias atuais por meio da aprendizagem móvel e toques de estratégias de gamificação buscando tornar leve um conteúdo que por muitos é cansativo.

Feito isto e após o empoderamento, não é de se estranhar que com o avanço deste conhecimento de forma coletiva, obtenha-se por conseguinte, uma melhoria da consciência tanto de consumidores quanto de fornecedores de produtos e serviços.

Para tanto, ficou evidenciado que o perfil destes consumidores, principalmente os que já sofreram algum problema na relação de consumo, é condizente com as novas tecnologias e está bastante receptivo quanto a possibilidade de se obter um aplicativo voltado para a aprendizagem que possa de forma simples ajudá-los na aquisição deste conhecimento para tornarem-se conscientes de que atitude tomar. O próximo passo será a elaboração do aplicativo levando-se em consideração as informações obtidas nos dados primários e secundários para que possa lograr êxito.

Por fim, a aplicabilidade do mobile learning concomitante com a gamificação para a promoção do conhecimento é mais que salutar, é necessária. Ela deixa a sala de aula com conteúdos tradicionais e toma destino rumo a promoção do conhecimento ao cidadão comum.

\section{Referências}

ALVES, L. R. G., HETKOWSKI, T. M., JAPIASSU, Ricardo. Trabajo colaborativo en la red. Madri: uned, 2006, v.01. p.72.

ANATEL. Tefonia Móvel - Acessos. Fonte: ANATEL: http://www.anatel.gov.br/dados/index.php?option=com_content\&view=article\&id=283

BORGES, S. D. Reis, H. M. Durelli, V. H. S. et al. Gamificação Aplicada à Educação: Um Mapeamento Sistemático, Congresso Brasileiro Informática na Educação - CBIE, páginas 234-243, 2013.

BRASIL. LEI No 8.078, DE 11 DE SETEMBRO DE 1990. Dispõe sobre a proteção do consumidor e dá outras providências. Disponível em: <http://www.planalto.gov.br/CCIVIL_03/leis/L8078.htm> Acesso em 10 jun. 2016.

DIANA, J. B., Golfetto, I. F., Baldessar, M. J. e Spanhol, F. J. (2014). Gamification e Teoria do Flow. In Fadel, L. M. et al. (Org.). "Gamificação na Educação" (pp. 38-73). São Paulo, Pimenta Cultural.

FERREIRA, H. N. M., Araújo, R. D., Souza, P. C., Júnior, S. C. S., Dorça, F. A., Cattelan, R. G. Gamificac,ao em Ambientes Educacionais Ubíquos. Anais do XXVI Simpósio Brasileiro de Informática na Educação (SBIE 2015).

GEDDES, S. (2004). Mobile learning in the 21st century: benefit for learners. http://knowledgetree.flexiblelearning.net.au/edition06/download/geddes.pdf. Acesso em 29 abr. 2016. 
V Congresso Brasileiro de Informática na Educação (CBIE 2016)

Anais dos Workshops do V Congresso Brasileiro de Informática na Educação (CBIE 2016)

GIL, Antônio Carlos. Como elaborar projetos de pesquisa. São Paulo: Atlas, 2007.

KAPP, K. M. The Gamification of Learning and Instruction: Game-based Methods and Strategies for Training. John Wiley \& Sons, 2012.

LÉVY, Pierre. Abrir o espaço semântico em prol da inteligência coletiva. Revista Eletrônica de Comunicação Informação \& Inovação em Saúde. Rio de Janeiro, v.1, n.1, p.129-140, jan.jun., 2007. Disponível em: http://www.reciis.icict.fiocruz.br/index.php/reciis/article/view/898 Acesso em 17 Mai. 2016.

. A inteligência coletiva: por uma antropologia do ciberespaço. 4.ed. São Paulo: Loyola. 2003.

MANZATO, A. J., Santos, A. B. A ELABORAÇÃO DE QUESTIONÁRIOS NA PESQUISA QUANTITATIVA. Departamento de Ciência de Computação e Estatística - IBILCE - UNESP. Disponível

em http://www.inf.ufsc.br/ verav/Ensino_2012_1/elaboracao_questionarios_pesquisa_quantitativa.pdf. Acesso em 19 Mai. 2016.

MARCONI, Marina de Andrade; LAKATOS, Eva Maria. Fundamentos da metodologia científica. 7. ed. São Paulo: Atlas, 2010, 297 p.

MARIETTA, G., Brooks, J., Hahn, E., Xu, M., Dede, C., Gehlbach, H. (2013). Encouraging compromise through perspective taking in virtual simulations. Poster presented at the American Psychological Association Conference, Honolulu, HI.

MAZETTI, H. O consumo consciente e a governamentalidade neoliberal. Mediação, v.14, n.14, p.97111, jan.jun. 2012. Disponível em $<$ http://www.fumec.br/revistas/index.php/mediacao/article/view/978/pdf $>$ Acesso em: 12 mai. 2015.

MCGONIGAL, Jane. Games. Disponível na URL: https://janemcgonigal.com/my-book/ . Acesso em 17 de Mai. 2016.

MCGONIGAL, Jane. Reality Is Broken: Why Games Make Us Better and How They Can Change the World. Nova York, Penguin Press, Ed. 1. 2011.

MORAES, H. J. P. Ineligência coletiva: o ciberespaço como retrato da sociedade ou uma discussão da ética da estética. Revista FAMECOS, mídia cultura e tecnologia. Porto Alegre. V. 18, n. 2, p. 542556, maio/agosto 2011.

OLIVEIRA, E. R., Diniz, J. R. B., Falcão, T. P. Ensino e Aprendizagem Através de Dispositivos Móveis no Ramo do Direito: uma Revisão Sistemática da Literatura. Congresso Regional sobre Tecnologias na Educação. Ctrl+E. UFRN. 2016

OLIVEIRA, E. R., Santos, M. S., Diniz, J. R. B., Souza, R. MOBILE LEARNING, UMA NOVA PERSPECTIVA NA PROMOÇÃO DOS DIREITOS DOS CONSUMIDORES. Congresso Brasileiro de Ensino Superior a Distância - ESUD. 2015 p. 319-331.

SALEN, Katie; ZIMMERMAN, Eric. Regras do Jogo - Fundamentos do Design de Jogos. Blucher, Vol. 1, Ed. 1. 2012.

SANTOS, Glauber Eduardo de Oliveira. Cálculo amostral: calculadora on-line. Disponível em: $<$ http://www.calculoamostral.vai.la $>$. Acesso em: 16 mai. 2016.

SANTOS, P.L.V.A.C. Redes informacionais como ambiente colaborativo e empoderamento: a catalogação em foco. In: GUIMARÃES, J.A.C.; FUJITA, M. S. L. (Org.). Ensino e Pesquisa em Biblioteconomia no Brasil: a emergência de um novo olhar. 2008.p.155-171.

TRAXLER, J. Current State of Mobile Learning. In Mobile Learning: Transforming the Delivery of Education and Training, AU Press, Athabasca University. Capítulo 1, P. 1-24. 2009.

TORRISI-Steele G. Pedagogical Perspectives on M-learning. Encyclopedia of Information Science and Technology, Mehdi Khosrow-Pour,USA 2009.

UNESCO. Reading in the Mobile Era. United Nations Educational, Scientific and Cultural Organization, Paris, France 2014 ISBN 978-92-3-100023-2

VEIGA W., Campos, F., Braga, R., David, J. M. LUDOS: uma Infraestrutura para Gamificação em Ecossistemas de E-learning. Anais do XXVI Simpósio Brasileiro de Informática na Educação (SBIE 2015).

VIANNA, Y.; VIANNA, M.; MEDINA, B.; TANAKA, S. Gamification, Inc. Como reinventar empresas a partir de jogos. Rio de Janeiro: MJV Press, 2013, 164 p. 